Audiol Neurotol 2015;20(suppl 1):31-37

DOI: $10.1159 / 000380745$

\section{Quantification of Speech-in-Noise and Sound Localisation Abilities in Children with Unilateral Hearing Loss and Comparison to Normal Hearing Peers}

Ruth M. Reeder ${ }^{\mathrm{a}}$, Jamie Cadieux ${ }^{\mathrm{b}}$, Jill B. Firszt ${ }^{\mathrm{a}}$

${ }^{a}$ Department of Otolaryngology, Head and Neck Surgery, Washington University School of Medicine, and ${ }^{\mathrm{b}} \mathrm{St}$. Louis Children's Hospital, St. Louis, Mo., USA

\section{Key Words}

Sound localisation · Spatial hearing $\cdot$ Speech recognition in noise Unilateral hearing loss

\begin{abstract}
The study objective was to quantify abilities of children with unilateral hearing loss (UHL) on measures that address known deficits for this population, i.e. speech understanding in quiet and noise, and sound localisation. Noise conditions varied by noise type and source location. Parent reports of real-world abilities were also obtained. Performance was compared to gender- and age-matched normal hearing $(\mathrm{NH})$ peers. UHL performance was poorer and more varied compared to $\mathrm{NH}$ peers. Among the findings, age correlated with localisation ability for UHL but not NH participants. Low-frequency hearing in the better ear of UHL children was associated with performance in noise; however, there was no relation for $\mathrm{NH}$ children. Considerable variability was evident in the outcomes of children with UHL and needs to be understood as future treatment options are considered.
\end{abstract}

(c) 2015 S. Karger AG, Basel

\section{Introduction}

Unilateral hearing loss (UHL) is a disruption in the auditory system, a system designed for binaural processing. Without the binaural cues that occur with normal hearing $(\mathrm{NH})$ bilaterally, there is no support for binaural summation, binaural squelch and selective attention to the ear with the better signal-to-noise ratio (SNR), all well-documented benefits of binaural hearing [Levitt and Rabiner, 1967; Durlach and Colburn, 1978; Haggard and Hall, 1982]. There is growing evidence that childhood UHL results in speech and language delays, impaired speech recognition in noise, reduced localisation abilities and compromised educational outcomes [Bess and Tharpe, 1988; Kenworthy et al., 1990; Lieu et al., 2010]. Lieu et al. [2010] reported that $22-35 \%$ of UHL children repeated a grade in school and $12-41 \%$ required additional educational support. Chil- dren with severe-to-profound UHL required at least 2-9 dB better SNRs than age-matched peers for understanding speech in noisy environments, which are common for children [Ruscetta et al., 2005]. Even in quiet, children with UHL have poorer syllable recognition than NH peers when speech is directed towards the unimpaired ear [Bess et al., 1986]. Accompanying the negative consequences of UHL is considerable unexplained individual variability. Identification of factors that affect outcomes and contribute to variability in UHL could augment counselling, treatment options and rehabilitation.

While it is common to recommend bilateral input for children with bilateral hearing loss of varied degrees, data are sparse with respect to the best recommendation for treating UHL. Particularly in the case of severe-to-profound hearing loss in the impaired ear, the likelihood of achieving a successful hearing aid fitting is slim. Outside the US, cochlear implantation as a treatment option for children with severe-to-profound UHL has gained recent attention [Hassepass et al., 2013; Plontke et al., 2013]. Before cochlear implant treatment can be recommended, it is essential that children's abilities be quantified on measures that address known deficits. This quantification serves as a baseline for performance and will assist as future treatments and associated candidacy decisions are considered.

The aim of this study was to quantify abilities of children with UHL on measures that address known deficits of this population; for example, speech understanding in quiet, speech understanding in noise and sound localisation. Parent reports of the children's abilities in real-world situations were also obtained. We compared the performance of UHL children to gender-matched $\mathrm{NH}$ peers of similar age. In addition, we investigated possible sources of variability contributing to outcomes observed in children with UHL.

\section{Participants}

All participants provided informed consent in compliance with the Code of Ethics of the World Medical Association (Declaration of Helsinki) and guidelines approved by the Human Research Protection Office at Washington University in St. Louis (ID No. 201102256).

Participants were 20 children with UHL and 20 children with $\mathrm{NH}$ bilaterally. Hearing levels for the poor ear of UHL participants were on average profound (100.8 dB HL) and ranged from moderately severe to profound. The two groups were of similar ages (mean age: 12.0 years for each group): the group range was 6.916.3 years for the UHL group and 7.5-17.8 years for the NH group. Table 1 provides additional participant information for these groups as well as for a subset of 11 participants in each group who completed two additional measures.

\section{Test Measures}

Word recognition was evaluated with $\mathrm{CNC}$ monosyllabic words [Peterson and Lehiste, 1962] in quiet at a soft conversational level (50 dB SPL) and in four-talker babble (4TB) at an average

\section{KARGER 125}

E-Mail karger@karger.com www.karger.com/aud (c) 2015 S. Karger AG, Base 1420-3030/15/0207-0031\$39.50/0

Karger $\checkmark$ pen access

This is an Open Access article licensed under the terms of the Creative Commons Attribution-NonCommercial 3.0 Unported license (CC BY-NC) (www.karger.com/OA-license), applicable to the online version of the article only. Distribution permitted for non-commercial purposes only. 
Table 1. Demographic and hearing history information of the participants

\begin{tabular}{cccccc}
\hline Participants & $\begin{array}{l}\text { Age at testing, } \\
\text { years }\end{array}$ & \multicolumn{2}{l}{ FFPTA, dB HL } & $\begin{array}{l}\text { Age at UHL } \\
\text { onset, years }\end{array}$ & $\begin{array}{l}\text { Length of } \\
\text { UHL, years }\end{array}$ \\
\cline { 3 - 4 } & poorer/right ear & better/left ear & & \\
\hline $\begin{array}{c}\text { UHL group } \\
\mathrm{n}=20\end{array}$ & $12.0(6.9-16.3)$ & $100.8(61-120+)$ & $6.6(-2$ to 20$)$ & $1.0(0.0-7.9)$ & $9.7(0.3-15.3)$ \\
$\mathrm{n}=11$ & $10.5(6.9-13.4)$ & $95.2(61-120+)$ & $5.9(-2$ to 20$)$ & $1.3(0.0-7.9)$ & $8.2(0.3-12.1)$ \\
NH group & & & & & \\
$\mathrm{n}=20$ & $12.0(7.5-17.8)$ & $4.2(0-17)$ & $4.9(-1$ to 16$)$ & & \\
$\mathrm{n}=10$ & $10.4(7.5-15.5)$ & $4.4(0-17)$ & $4.7(-1$ to 12$)$ & & \\
\hline
\end{tabular}

The first row of each group includes the complete set of participants. The second row indicates information for the subset of participants who were administered the additional sound localisation and adaptive SRT measures. $\mathrm{n}=$ Number of participants; FFPTA $=$ full-frequency pure-tone average from 250 to $8,000 \mathrm{~Hz}$ for the poorer ear of UHL participants or right ear of $\mathrm{NH}$ participants in one column and better ear of UHL participants or left ear of $\mathrm{NH}$ participants in one column. conversational level ( $60 \mathrm{~dB}$ SPL $+8 \mathrm{~dB}$ SNR). Speech understanding in noise was evaluated using sentences of the Hearing in Noise Test [Nilsson et al., 1994] in the R-space [Revit et al., 2002; Compton-Conley et al., 2004]. The R-space consists of eight, equally spaced loudspeakers encircling the participant. Each loudspeaker was approximately at ear level and two feet from the centre of the listener's head. Sentences were presented from the front loudspeaker and $60 \mathrm{~dB}$ SPL restaurant noise from all loudspeakers. The sentence level was adapted based on participant responses to yield an SNR for $50 \%$ accuracy (SNR-50).

Sound localisation was evaluated among the participant subset with a $140^{\circ}$ arc of 15 loudspeakers, each $10^{\circ}$ apart. Stimuli were the carrier 'ready' followed by a monosyllabic word, 100 words in total and an equal number of words pseudo-randomly presented from each active loudspeaker. Participants were blinded to the fact that only 10 of the loudspeakers were active $\left( \pm 70, \pm 50, \pm 30, \pm 20\right.$ and $\left.\pm 10^{\circ}\right)$. A root mean square (RMS) error score was calculated as the mean target-response difference irrespective of error direction. Lower scores indicated less error (greater accuracy).

An adaptive speech reception threshold (SRT) psychoacoustic task (adapted from that used by Johnstone and Litovsky [2006] and Litovsky [2005]) was administered to the participant subset in three-loudspeaker configurations. Test spondees were administered from the front loudspeaker. Noise, when present, was presented from either the front, or from loudspeakers placed $90^{\circ}$ to the right or $90^{\circ}$ to the left of the listener. Noise was either single-talker (male or female) or multitalker babble (MTB) at $60 \mathrm{~dB}$ SPL. For each spondee presentation, the background (quiet or one of the three talker types) was pseudo-randomised, which added uncertainty for the listener. A four-alternative forced-choice adaptive task (using a picture format) resulted in nine SRTs, one for each noise type (male, female and $\mathrm{MTB}$ ) and noise source (front, right and left) combination plus one SRT for quiet.

A modified version of the Speech, Spatial and Qualities of Hearing Scale (SSQ) questionnaire [Gatehouse and Noble, 2004; Galvin et al., 2007] was administered to participants' parents as a reflection of their child's real-world hearing performance. The SSQ questionnaire assesses performance in three domains, hearing speech in quiet and noise environments (9 items), spatial or direc-

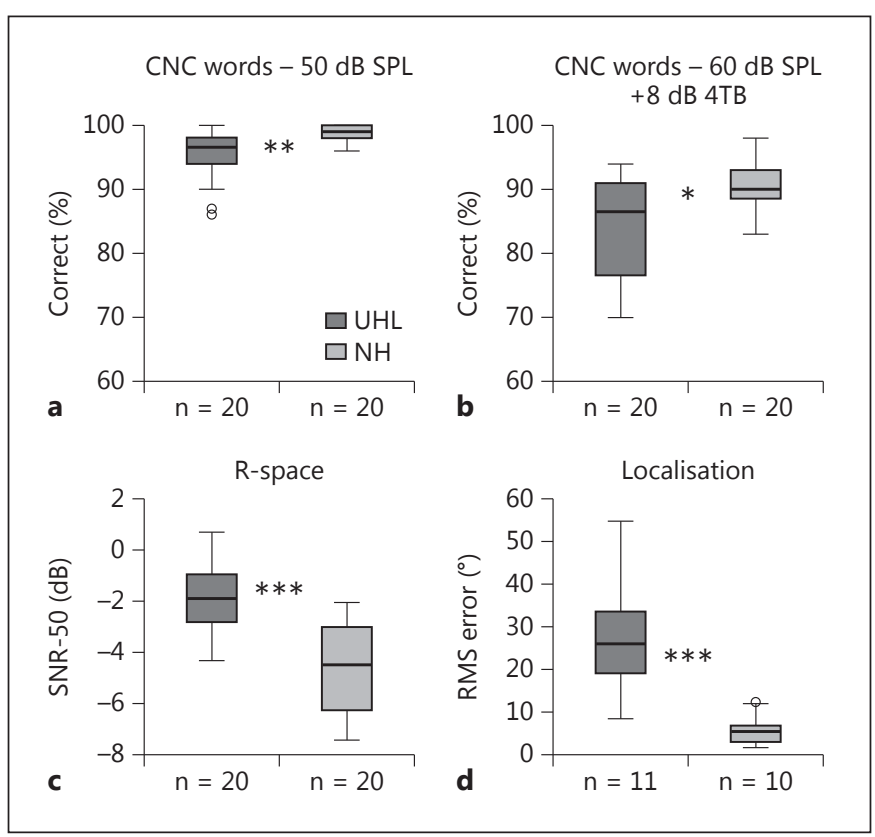

Fig. 1. Box plots indicate the medians (bold horizontal line), interquartile ranges (box) and 10th-90th percentiles (whiskers) for speech recognition $(\mathbf{a}-\mathbf{c})$ and localisation (d) performance for UHL (dark grey) and NH (light grey) participant groups. Scores beyond the 10th-90th percentiles are indicated with circles (UHL; a). Note that lower SNR-50 (c) and RMS error (d) scores indicate better performance. ${ }^{*} \mathrm{p}<0.05,{ }^{* *} \mathrm{p}<0.01,{ }^{* * *} \mathrm{p}<0.001$.

tional hearing (5 items) and sound qualities (8 items), which address sound segregation and listening effort. Each item was rated on a 10-point scale (higher scores reflect higher ability). Domain scores represent an average of item ratings.

Group means were compared with Bonferroni's adjusted t tests or repeated-measure ANOVAs. Pearson's correlations were used to analyse relationships between variables. Statistical significance was set at $\mathrm{p}<0.05$. 


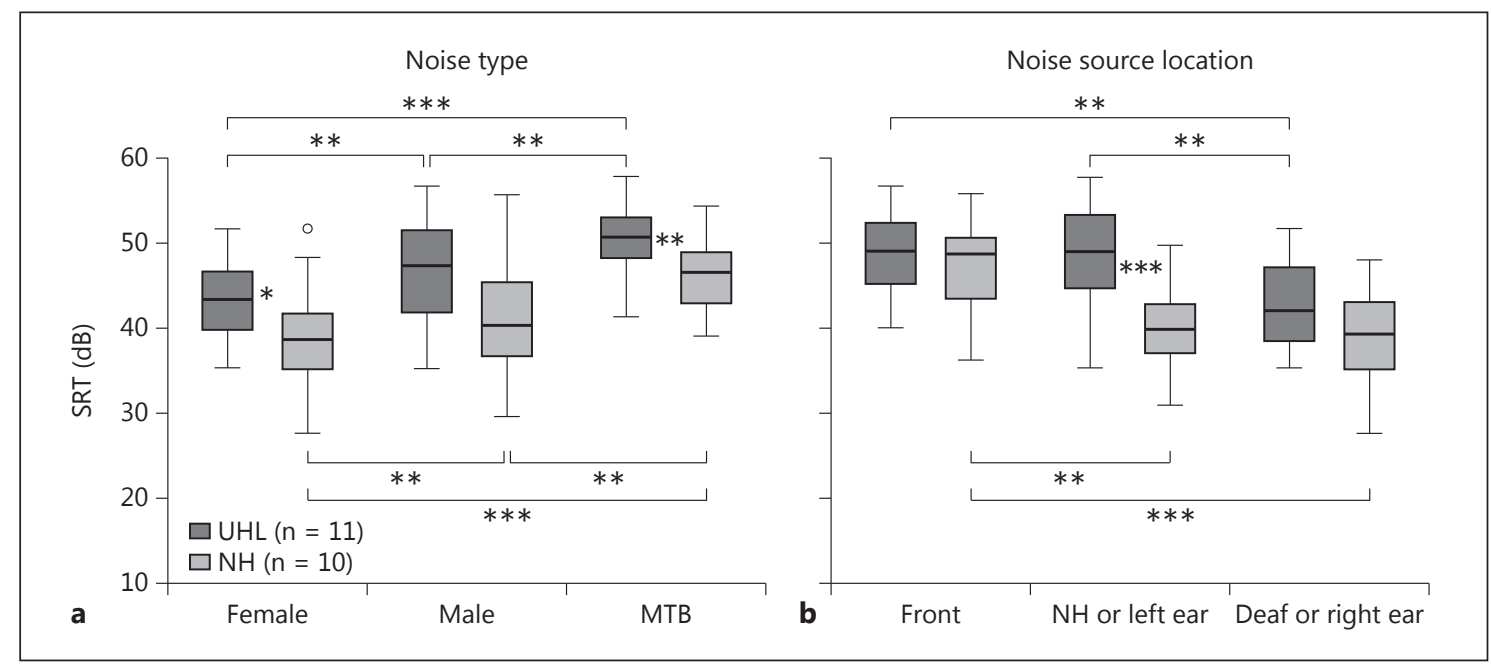

Fig. 2. Box plots indicate the median (bold horizontal line), interquartile range (box), and 10th-90th percentile (whiskers) SRTs for UHL (dark grey) and NH (light grey) participant groups. Scores $>1.5$ times the interquartile range are indicated with a circle. Performance is displayed by noise type (a) and noise source location (b). Note that lower SRT scores indicate better performance. ${ }^{* *} \mathrm{p}<0.01,{ }^{* * *} \mathrm{p}<0.001$.

\section{Results}

Figure 1 shows group medians and ranges of responses for word recognition in quiet (fig. 1a), word recognition in noise (fig. 1b), sentence recognition in noise in the R-space (fig. 1c) and sound localisation (fig. 1d). In all panels (as well as in fig. 2, 3), UHL group results are indicated in dark grey and $\mathrm{NH}$ group results in light grey. There was a significant group difference with means of the UHL group significantly poorer than in the NH group: words in quiet UHL mean $=95 \%(\mathrm{SD} 4 \%), \mathrm{NH}$ mean $=99 \%(\mathrm{SD} 1 \%)$, $\mathrm{t}(38)=-4.04, \mathrm{p}<0.01$; words in noise UHL mean $=84 \%($ SD $8 \%)$, $\mathrm{NH}$ mean $=90 \%(\mathrm{SD} 4 \%), \mathrm{t}(38)=-3.10, \mathrm{p}<0.05$; sentences in noise $\mathrm{UHL}$ mean $=-2.0 \mathrm{~dB}(\mathrm{SD} 1.4 \mathrm{~dB})$, NH mean $=-4.6 \mathrm{~dB}(\mathrm{SD} 1.7 \mathrm{~dB})$, $\mathrm{t}(38)=5.26, \mathrm{p}<0.001$; localisation UHL mean $=28.1^{\circ}\left(\mathrm{SD} \mathrm{13.5^{ \circ }}\right)$, $\mathrm{NH}$ mean $=6.0^{\circ}\left(\mathrm{SD} 3.7^{\circ}\right), \mathrm{t}(19)=4.99, \mathrm{p}<0.001$.

Adaptive SRTs in quiet were not significantly different between the two groups, UHL mean $=23.2 \mathrm{~dB}(\mathrm{SD} 5.1 \mathrm{~dB}), \mathrm{NH}$ mean $=17.7$ $\mathrm{dB}(\mathrm{SD} 8.4 \mathrm{~dB}), \mathrm{t}(19)=1.84, \mathrm{p}>0.05$. Adaptive SRTs in noise are shown in figure $2 \mathrm{a}$ by noise type (female talker, male talker and MTB). In figure $2 b$, noise source location results are shown for the front location (fig. 2b: left side), when noise was towards the $\mathrm{NH}$ ear of UHL or left ear of NH participants (fig. 2b: centre) or when noise was towards the deaf ear of UHL or right ear of $\mathrm{NH}$ participants (fig. 2b: right side). A three (noise type) by three (noise location) by two (group) ANOVA with noise type and location treated as repeated measures indicated a significant group effect, $\mathrm{F}(1,19)=9.98, \mathrm{p}<0.01$, and a significant effect of both noise type, $\mathrm{F}(2,38)=75.68, \mathrm{p}<0.001$, and noise source location, $\mathrm{F}(2,38)=$ $38.01, \mathrm{p}<0.001$, as well as a significant group by source interaction, $\mathrm{F}(2,38)=9.11, \mathrm{p}<0.01$. Post hoc analysis identified significant differences between UHL and NH participants for female talker noise ( $p<0.05)$ and MTB ( $<<0.01$; fig. $2 \mathrm{a}$ ), and noise from the side of the $\mathrm{NH}$ or left ear ( $<<0.001$; fig. $2 \mathrm{~b})$. For both groups, there was a significant difference between each of the three noise types (fig. 2a); scores were poorer for MTB than male talker noise, and male talker noise scores were poorer than female talker noise

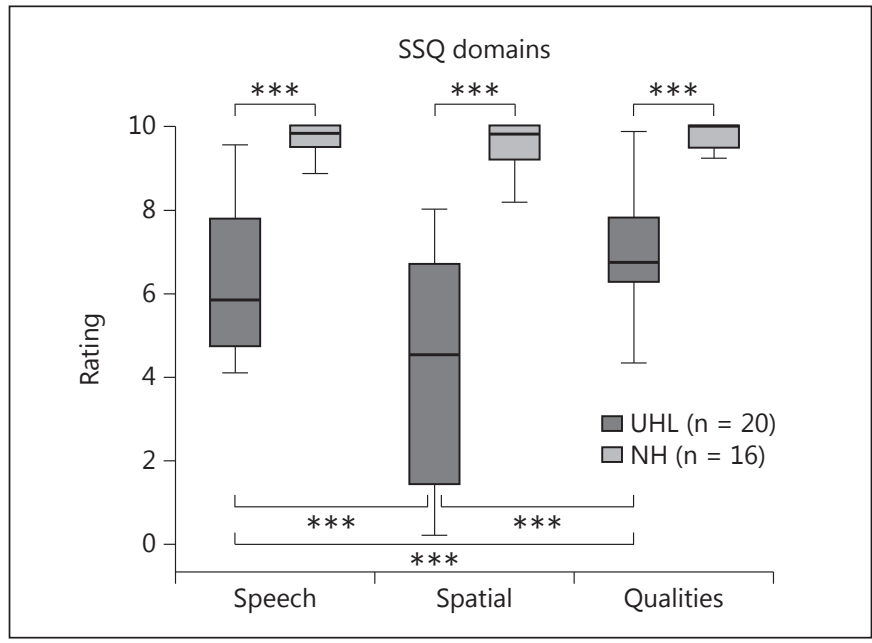

Fig. 3. Box plots indicate the median (bold horizontal line), interquartile range (box), and 10th-90th percentile (whiskers) SSQ ratings for UHL (dark grey) and NH (light grey) participant groups. $* * * \mathrm{p}<0.001$.

( $p<0.01$, respectively). As seen in figure $2 \mathrm{~b}$ for the $\mathrm{NH}$ group, noise from the front was significantly more difficult than noise from either side $(\mathrm{p}<0.01)$, and there was no significant difference in performance based on noise from the right or left side $(\mathrm{p}>0.05)$. This differed from the UHL group for whom scores with noise from the deaf ear were significantly better than noise from the $\mathrm{NH}$ ear side or front ( $p<0.01$, respectively), and there was no significant difference in performance between those two noise source locations ( $\mathrm{p}>0.05)$.

Figure 3 shows SSQ results by domain for UHL and NH participants. A three (domain) by two (group) ANOVA with do- 
Fig. 4. Scatter plots and correlations between outcomes [word recognition in quiet $(\mathbf{a}, \mathbf{b})$; word recognition in noise $(\mathbf{c}, \mathbf{d})$ and sound localisation $(\mathbf{e}, \mathbf{f})$ ] and age are plotted for UHL (a, c, e) and NH (b, d, f) participants. Significant correlations ( $r$ and $p$ values) and number of participants are shown on the plot.

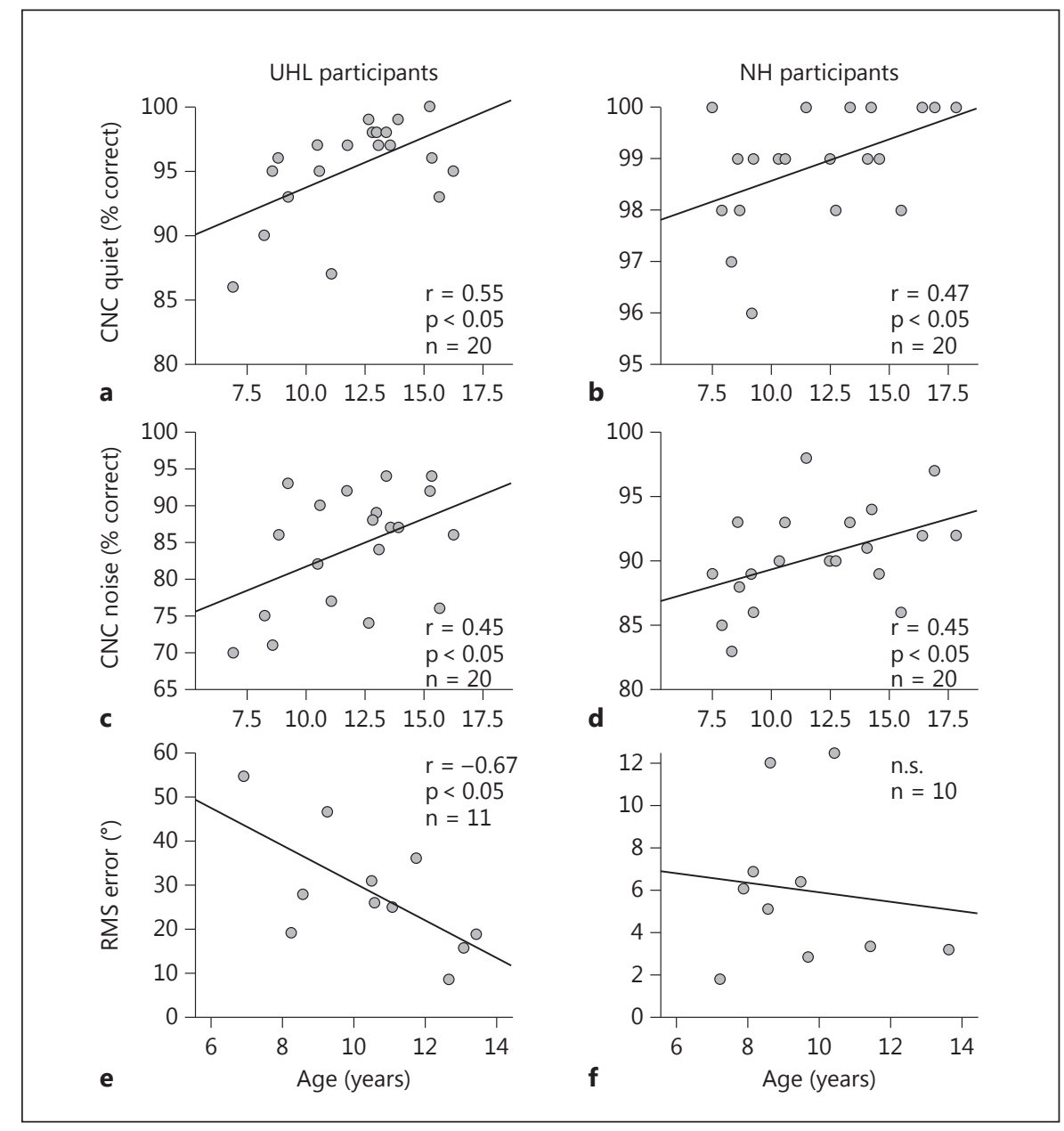

main as a repeated measure indicated a significant group effect, $\mathrm{F}(1,34)=66.02, \mathrm{p}<0.001$, domain effect, $\mathrm{F}(2,68)=24.87, \mathrm{p}<$ 0.001 , and group by domain interaction, $\mathrm{F}(2,68)=19.10, \mathrm{p}<0.001$. Bonferroni's adjusted post hoc pairwise comparisons identified $\mathrm{NH}$ group ratings as significantly higher than UHL group ratings $(\mathrm{p}<0.001)$ on all three domains. For the UHL group, quality ratings (mean $=7.0, \mathrm{SD}=1.5$ ) were significantly higher than speech ratings (mean $=6.2, \mathrm{SD}=1.7$ ), which were significantly higher than spatial ratings (mean $=4.3, \mathrm{SD}=2.8$ ), $\mathrm{p}<0.001$, respectively. There were no significant domain differences within the $\mathrm{NH}$ group ( $\mathrm{p}>0.05$ ); means ranged from 9.5 to 9.7 .

Correlation analysis assessed the relationship between age, two measures of the $\mathrm{NH}$ ear's hearing acuity (full-frequency pure-tone average and the $500-\mathrm{Hz}$ threshold) and outcomes. Figure 4 plots age versus word recognition and localisation outcomes. Significant correlations were present between age and $\mathrm{CNC}$ word scores in quiet for UHL $(\mathrm{r}=0.55, \mathrm{p}<0.05)$ and $\mathrm{NH}(\mathrm{r}=0.47, \mathrm{p}<0.05)$ participants, between age and CNC word scores in noise for UHL $(\mathrm{r}=0.45, \mathrm{p}<0.05)$ and $\mathrm{NH}(\mathrm{r}=0.45, \mathrm{p}<0.05)$ participants, and between age and localisation ability for UHL participants $(\mathrm{r}=$ $-0.67, \mathrm{p}<0.05$ ). Age did not significantly correlate with $\mathrm{NH}$ localisation ability or with R-space and adaptive SRTs for either group. Figure 5 illustrates the relationship between low-frequency hearing and adaptive SRTs for the UHL participants. Low-frequency hearing correlated with the two single-talker noise-type SRTs (female $\mathrm{r}=0.71$ and male $\mathrm{r}=0.64, \mathrm{p}<0.05$, respectively) and two noise source location SRTs (front $\mathrm{r}=0.79, \mathrm{p}<0.01$, and $\mathrm{NH}$ ear $r=0.71, p<0.05$ ) for the UHL group (fig. 5). Low-frequency hearing did not correlate with any other UHL or NH outcomes. No significant correlations were identified between full-frequency pure-tone average and outcomes for either group, nor for the UHL group between age at onset or duration of hearing loss and any outcome. Finally, correlations were analysed between localisation scores and the other measures. The only significant correlation with localisation was R-space scores for the NH group $(r=0.67$, $\mathrm{p}<0.05$ ) and adaptive SRTs (female $\mathrm{r}=0.71, \mathrm{p}<0.05$; male $\mathrm{r}=$ $0.76, \mathrm{p}<0.05$, and front $\mathrm{r}=0.80, \mathrm{p}<0.01$ ) for the UHL group.

\section{Discussion}

This study evaluated speech understanding in quiet, speech understanding in noise using varied noise types and noise locations, sound localisation abilities, and parents' perception of abilities during everyday listening for children with UHL and age- and gender-matched NH peers. Children with UHL had one NH ear and one ear with, on average, profound hearing loss. Hearing thresh- 
Fig. 5. Scatter plots and correlations between SRTs by noise type (a, $\mathbf{c}, \mathbf{e})$ and noise source location $(\mathbf{b}, \mathbf{d}, \mathbf{f})$ and $500-\mathrm{Hz}$ thresholds of the NH ear are plotted for UHL participants $(n=11)$. Significant correlations are indicated.
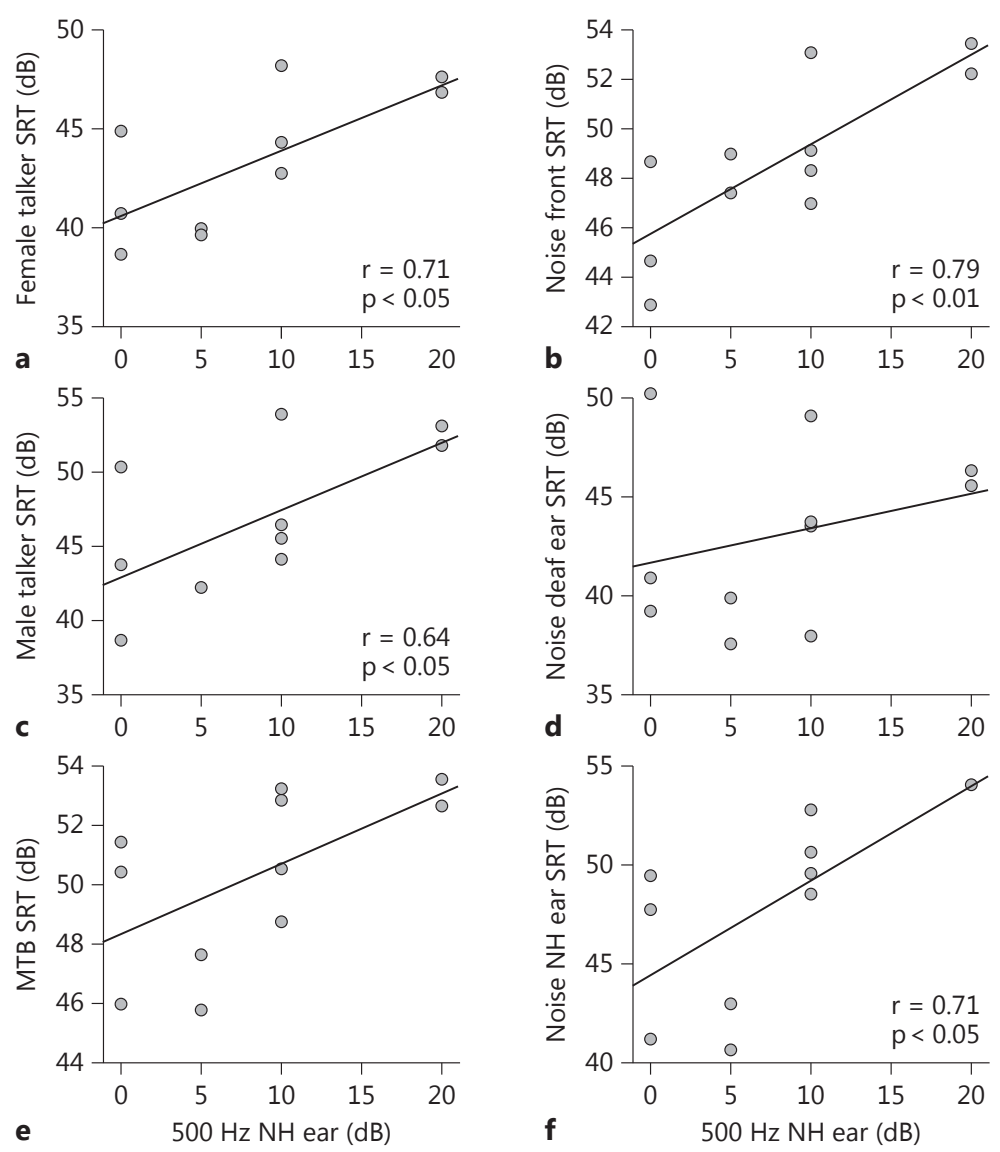

olds of the better ear of UHL children and of either ear of NH children did not differ. On most measures, outcomes for children with UHL were degraded and often more varied compared to $\mathrm{NH}$ peers. Even in quiet with words presented from the front, recognition was reduced compared to NH controls. UHL was associated with significantly poorer speech understanding in noise for word recognition in babble and in female talker noise. Results from the adaptive SRT task showed that when noise was located at the front, there were no differences between the hearing groups. For children with $\mathrm{NH}$, as soon as the noise was moved to the right or left, there was improvement in word recognition. For children with UHL, however, only one location improved word understanding in noise: that was when the noise was moved towards the deaf ear. The mean difference between UHL and NH groups on the R-space task using sentence stimuli was $2.6 \mathrm{~dB}$, a SNR comparable to $23 \%$ poorer speech intelligibility for UHL children [House Ear Institute, 1995]; this would represent a very meaningful difference in everyday listening. As expected, localisation performance was significantly poorer and more varied for children with UHL compared to agematched NH peers. Results between hearing groups on measures of speech understanding and localisation were supported by parental report of communication difficulties in real-world environments (SSQ).
A second objective was to investigate possible sources of variability that contribute to performance in children with UHL. Age correlated with localisation abilities of the UHL but not the NH children. In studies where localisation is measured using the minimum audible angle or the smallest angular change that can be discerned when sounds are separated, children with $\mathrm{NH}$ showed performance similar to adults by age 5 years [Litovsky, 1997]. Likewise, in the current study with the youngest children approximately 7 years of age the mean performance was similar to that of a group of $\mathrm{NH}$ adults $\left[\mathrm{n}=23\right.$; mean $\mathrm{RMS}$ error $=3.4^{\circ} ; \mathrm{SD}=2.5^{\circ}$; Firszt et al., unpubl. data]. These NH children, on average, had reached near adult-level performance whereas the UHL group results suggest that in this population improvements may continue to occur with age, well past 5 or 7 years of age. Johnstone et al. [2010] also noted that among UHL children, older children performed better than younger children. It is likely that children with UHL learn localisation strategies over time, although performance is still poorer than in $\mathrm{NH}$ peers. Improvements in localisation with experience have also been reported in children with bilateral, sequential cochlear implants [Litovsky et al., 2006]. Of interest in the current study, age correlated with localisation and not with adaptive SRTs for the UHL group; however, localisation and three of the adaptive SRTs correlated. This suggests an additional compo- 
nent along with age factors into localisation abilities for UHL participants and warrants further investigation.

Age also correlated with word recognition in quiet and noise regardless of the hearing group. Younger children in both groups performed more poorly than older children, suggesting a developmental factor, although the monosyllable words should have been within the children's vocabulary level given the children's ages [Madell and Flexer, 2014]. Even in NH, studies have shown that younger children require a greater SNR than older children when listening in noise [Johnson, 2000; Bradley and Sato, 2008]. It is possible that there is a similar developmental aspect for listening to soft speech. Another demographic variable associated with performance for UHL children, specifically the adaptive SRT measure, was low-frequency hearing thresholds. For the UHL group, better low-frequency hearing was associated with lower SRTs in noise unless noise was from the side of the deaf ear. This finding was true for both female and male talker noise; the result with MTB for this small sample size almost reached statistical significance $(r=0.60$, $\mathrm{p}=0.052$ ). There were no correlations between low-frequency hearing levels and SRTs in noise for children with NH. Perhaps, a few decibels difference in hearing has a greater impact when listening with a single ear than with two ears. While monaural low-frequency hearing supported better understanding in noise for UHLs, it did not support improved localisation. Low-frequency thresholds of the better ear did not correlate with localisation accuracy.

Although UHL performance was poorer than that of the $\mathrm{NH}$ peers, there were some UHL participants whose scores were within the NH group range on all measures except the spatial SSQ. This highlights the variable results among UHL paediatric listeners and points to some children being more vulnerable to the effects of monaural listening than others. Further study is needed to understand and differentiate between children who are greatly affected by UHL from those who are more minimally affected. This is particularly important when considering treatment options for UHL children. In cases of severe-to-profound UHL, traditional amplification to the poorer ear has been unsuccessful. Although CROS (contralateral routing of the signal) may be beneficial in some situations, it does not restore hearing to the poor ear and, in some cases, has been detrimental [Hol et al., 2004; Wazen et al., 2005; Hol et al., 2010]. Cochlear implantation as a treatment for adults with UHL is on the rise [Buechner et al., 2010; Arndt et al., 2011; Jacob et al., 2011; Firszt et al., 2012; Ramos et al., 2012], yet little is known about factors that could impact performance or whether there is a group at risk for poor outcomes when hearing is near normal in one ear. Likewise in children with UHL, predictive variables for cochlear implant success are unknown, and whether these factors change developmentally has not been determined.

\section{Acknowledgements}

This work was supported by NIH/NIDCD R01DC 009010. We thank Judy Lieu and the paediatric audiologists at St. Louis Children's Hospital for assistance with participant recruitment. We appreciate the time and commitment given by the participants and their families during this study.

\section{Disclosure Statement}

The authors have nothing to disclose.

\section{References}

-Arndt S, Laszig R, Aschendorff A, Beck R, Schild C, Hassepass F, Ihorst G, Kroeger S, Kirchem P, Wesarg T: Unilateral deafness and cochlear implantation: audiological diagnostic evaluation and outcomes (in German). HNO 2011;59:437-446.

Bess FH, Tharpe AM: Performance and management of children with unilateral sensorineural hearing loss. Scand Audiol Suppl 1988;30:75-79.

Bess FH, Tharpe AM, Gibler AM: Auditory performance of children with unilateral sensorineural hearing loss. Ear Hear 1986;7:20-26.

Bradley JS, Sato H: The intelligibility of speech in elementary school classrooms. J Acoust Soc Am 2008;123:2078-2086.

Buechner A, Brendel M, Lesinski-Schiedat A, Wenzel G, Frohne-Buechner C, Jaeger B, Lenarz T: Cochlear implantation in unilateral deaf subjects associated with ipsilateral tinnitus. Otol Neurotol 2010;31:1381-1385.

Compton-Conley CL, Neuman AC, Killion MC, Levitt H: Performance of directional microphones for hearing aids: real-world versus simulation. J Am Acad Audiol 2004; 15:440-455.

Durlach NJ, Colburn HS: Binaural Phenomena: Handbook of Perception. San Diego, Academic Press, 1978, pp 373-406.

Firszt JB, Holden LK, Reeder RM, Waltzman SB, Arndt S: Auditory abilities after cochlear implantation in adults with unilateral deafness: a pilot study. Otol Neurotol 2012;33:1339-1346.

Galvin KL, Mok M, Dowell RC: Perceptual benefit and functional outcomes for children using sequential bilateral cochlear implants. Ear Hear 2007; 28:470-482.

Gatehouse S, Noble W: The speech, spatial and qualities of hearing scale (SSQ). Int J Audiol 2004;43:85-99.

Haggard MP, Hall JW: Forms of binaural summation and the implications of individual variability for binaural hearing aids. Scand Audiol Suppl 1982;15:47-63.

Hassepass F, Schild C, Aschendorff A, Laszig R, Maier W, Beck R, Wesarg T, Arndt S: Clinical outcome after cochlear implantation in patients with unilateral hearing loss due to labyrinthitis ossificans. Otol Neurotol 2013; 34:1278-1283.

Hol MK, Bosman AJ, Snik AF, Mylanus EA, Cremers CW: Bone-anchored hearing aid in unilateral inner ear deafness: a study of 20 patients. Audiol Neurootol 2004;9:274-281.

Hol MK, Kunst SJ, Snik AF, Cremers CW: Pilot study on the effectiveness of the conventional CROS, the transcranial CROS and the BAHA transcranial CROS in adults with unilateral inner ear deafness. Eur Arch Otorhinolaryngol 2010;267:889-896.

House Ear Institute: Hearing in Noise Test Manual 2. Eden Prairie, Starkey Laboratories, 1995, p 21.

Jacob R, Stelzig Y, Nopp P, Schleich P: Audiological results with cochlear implants for single-sided deafness (in German). HNO 2011;59:453-460.

Johnson CE: Children's phoneme identification in reverberation and noise. J Speech Lang Hear Res 2000;43:144-157.

Johnstone PM, Litovsky RY: Effect of masker type and age on speech intelligibility and spatial release from masking in children and adults. J Acoust Soc Am 2006;120:2177-2189.

Johnstone PM, Nabelek AK, Robertson VS: Sound localization acuity in children with unilateral hearing loss who wear a hearing aid in the impaired ear. J Am Acad Audiol 2010;21:522-534.

Kenworthy OT, Klee T, Tharpe AM: Speech recognition ability of children with unilateral sensorineural hearing loss as a function of amplification, speech stimuli and listening condition. Ear Hear 1990;11:264-270.

Levitt H, Rabiner LR: Binaural release from masking for speech and gain in intelligibility. J Acoust Soc Am 1967;42:601-608.

Lieu JE, Tye-Murray N, Karzon RK, Piccirillo JF: Unilateral hearing loss is associated with worse speech-language scores in children. Pediatrics 2010;125:e1348-e1355.

Litovsky RY: Developmental changes in the precedence effect: estimates of minimum audible angle. J Acoust Soc Am 1997;102:1739-1745.

Litovsky RY: Speech intelligibility and spatial release from masking in young children. J Acoust Soc Am 2005;117:3091-3099. 
Litovsky RY, Johnstone PM, Godar S, Agrawal S, Parkinson A, Peters R, Lake J: Bilateral cochlear implants in children: localization acuity measured with minimum audible angle. Ear Hear 2006;27:43-59.

Madell JR, Flexer C: Pediatric Audiology: Diagnosis, Technology and Management, ed 2. New York, Thieme Medical Publishers, 2014, pp 99-100.

Nilsson M, Soli SD, Sullivan JA: Development of the hearing in noise test for the measurement of speech reception thresholds in quiet and in noise. J Acoust Soc Am 1994;95:1085-1099.

-Peterson GE, Lehiste I: Revised CNC lists for auditory tests. J Speech Hear Disord 1962;27:62-70.

- Plontke SK, Heider C, Koesling S, Hess S, Bieseke L, Goetze G, Rahne T: Cochlear implantation in a child with posttraumatic single-sided deafness. Eur Arch Otorhinolaryngol 2013;270:1757-1761.

-Ramos A, Polo R, Masgoret E, Artiles O, Lisner I, Zaballos ML, Moreno C, Osorio A: Cochlear implant in patients with sudden unilateral sensorineural hearing loss and associated tinnitus. Acta Otorrinolaringol Esp 2012;63:15-20.
Revit LJ, Schulein RB, Julsrom SD: Toward accurate assessment of real-world hearing aid benefit. Hear Rev 2002;9:34-38, 51.

Ruscetta MN, Arjmand EM, Pratt SR: Speech recognition abilities in noise for children with severe-to-profound unilateral hearing impairment. Int J Pediatr Otorhinolaryngol 2005;69:771-779.

Wazen JJ, Ghossaini SN, Spitzer JB, Kuller M: Localization by unilateral BAHA users. Otolaryngol Head Neck Surg 2005;132:928-932.

Corresponding author:

Jill B. Firszt, PhD

Department of Otolaryngology, Head and Neck Surgery

Washington University School of Medicine

660 South Euclid Avenue, St. Louis, MO 63110-1010 (USA)

E-Mail firsztj@ent.wustl.edu 